\title{
Buddhism and Cognitive Science: How Can the Dialogue Move Forward?
}

\author{
Keynote Lecture for the Conference "Buddhism, Mind, and Cognitive Science" \\ University of California, Berkeley \\ April 25, 2014. \\ Evan Thompson \\ University of British Columbia
}

The main proposition of my lecture is that the Buddhism-cognitive science encounter needs to be fundamentally reoriented in order to have a chance of becoming a genuine dialogue. At present, the encounter takes its direction from scientific research on meditation and gives primacy to the measurable biological and behavioural effects of meditation practices in controlled experimental and clinical situations. Although this research is worthwhile, it is neither the same as nor sufficient for a dialogue between Buddhism and cognitive science about the mind. I intend to argue that the Buddhismcognitive science encounter should take its direction from philosophy and give primacy to the constitution of meaning in human experience. Buddhist philosophy especially must be central to this dialogue.

\section{The Embodied Mind}

To set the context, I would like to go back to the book, The Embodied Mind: Cognitive Science and Human Experience, which I wrote with Francisco Varela and Eleanor Rosch almost twenty-five years ago. Since this book helped launch the Buddhism-cognitive science discussion, and since parts of it were written here at Berkeley, it seems fitting to begin by recalling some of its main ideas in relation to our conference theme, "Buddhism, Mind, and Cognitive Science." I would also like to take this opportunity to explain what I now see as the book's limitations.

Our aim in The Embodied Mind was to create what we called a circulation between cognitive science and human experience. Cognitive science tells us that the processes that bring about our experience of the world, including our sense of self, are dynamical, distributed in space and time, and extend across the complex couplings of the brain, the rest of the body, and the environment. Although it may seem as if there is a single, abiding self that functions as the controller of the mind, cognitive science indicates that what we call the mind is a collection of constantly changing, emergent processes that arise within a complex system comprising the brain, the rest of the body, and the physical and social environment, and in which we find no single, abiding, and controlling self. How are we to make sense of these discoveries in relation to our lived experience? However we choose to answer this question, we cannot do so without relying in some way on some kind of phenomenology, that is, on some kind of descriptive account of the meaningfulness of lived experience in the everyday world. Yet where are we going to find this phenomenology? One place to look is the Western tradition of phenomenological philosophy inaugurated by Husserl and carried forward by Heidegger and Merleau-Ponty. We argued, however, that this tradition had gotten bogged down in abstract, theoretical reflection and had lost touch with its original inspiration to examine 
lived experience in a rigorous way. For this reason, we turned to Buddhist philosophy and psychology, which we believed were based on attending scrupulously to experience through meditation. We focused on two interrelated Buddhist ideas. One idea was that of no-self or not-self - that the sense of an abiding, controlling self is a construct arising from certain deep-seated cognitive and emotional tendencies to impute permanence and singleness to what is impermanent and multiple. The other idea was that of dependent origination - that all phenomena arise dependent on causes and conditions, and therefore phenomena lack substantial being. We argued that these ideas could help make sense of our lived experience in the everyday world in relation to the findings of cognitive science, while also correcting the tendency within cognitive science to dismiss our experience outright as an epiphenomenal illusion. In this way, we juxtaposed three traditions - cognitive science, Western phenomenology, and Buddhism - and we used Buddhist philosophy and psychology to enrich phenomenology in ways that could also advance cognitive science. To use a hermeneutic term of art, our aim was to "fuse the horizons" of cognitive science, phenomenology, and Buddhism. On the one hand, we aimed to enlarge the horizon of cognitive science to include lived human experience and the possibilities for transformation inherent in human experience-specifically, the possibility of our not being held hostage to the reification of an abiding self, but without our falling into the nihilistic denial of the everyday self, to which cognitive science remains especially prone. On the other hand, we aimed to enlarge the horizon of human experience to include the insights into cognition, the body, and the self from cognitive science. Buddhist philosophy and the phenomenological importance of mindfulness meditation were among the critical new resources we brought to this effort.

Now for the book's limitations. Since I am going to draw from Western phenomenology and Buddhist philosophy in this lecture, I need to make clear that I no longer find acceptable three of the rhetorical and argumentative strategies we used in The Embodied Mind.

The first strategy was our portrayal of Western phenomenology as a failed or broken down philosophical project. On the contrary, Western phenomenology remains a vital and important movement, of continuing relevance to philosophy and cognitive science, as I've argued in my book, Mind in Life.

The second strategy was our depiction of Buddhist philosophy as based on meditation. This is too simplistic. As Buddhist scholars have discussed, many factors shaped the evolution of Indo-Tibetan Buddhist philosophical ideas, such as doctrinal constraints, scholastic argumentation, and the need to respond to non-Buddhist philosophers, so we cannot suppose that Indo-Tibetan Buddhist philosophical ideas were derived directly from meditation, though the extent to which they might have been informed by meditation remains an open question. In any case, classical Indian Buddhist philosophy was certainly not based on the kind of Buddhist modernist form of meditation that we called "mindfulness/awareness." Furthermore, Buddhist philosophy is every bit as abstract, theoretical, and technical as Western phenomenology and philosophy of mind, and this is a strength, not a weakness.

The third strategy was our tendency sometimes to depict mindfulness as a special kind of inner observation of a mental stream whose phenomenal character is independent of such observation. Since we are at UC Berkeley, I would like to take this occasion to mention that Hubert Dreyfus, in his review of The Embodied Mind, rightly objected to 
this conception of phenomenology as inward observation. As he pointed out, such an effort of inward observation alters experience, so no valid claim can be made on the basis of such observation about how experience is apart from such observation. Moreover, reading the results of such inward observation back into world-immersed, embodied experience would inevitably distort such experience. Besides wishing to acknowledge Dreyfus's criticism on this occasion, I mention it now because the Buddhism-cognitive science encounter remains influenced by the idea of Buddhist mindfulness practice as offering a special kind of introspection that can serve the purposes of the cognitive neuroscience of consciousness. Although I do think that mindfulness practices may facilitate a distinctive kind of awareness of what phenomenologists such as MerleauPonty call the "phenomenal field" of lived experience, I think it is mistaken to think of this kind of awareness as inward observation in any introspectionist sense of "inward." I will return to this point later.

The Embodied Mind also contained another, different conception of mindfulness meditation. According to this conception, mindfulness practices should be understood as skillful ways of enacting certain kinds of embodied states and behaviours in the world, not as inner observation of an independent mental stream. This conception connects to the central idea of The Embodied Mind, namely, the view of cognition that we called "enaction" or the "enactive approach."

In formulating the enactive approach, we drew on multiple sources - the theory of living organisms as self-producing or autopoietic systems that bring forth their own cognitive domains; newly emerging work on embodied cognition (how sensorimotor interactions with the world shape cognition); Merleau-Ponty's phenomenology of the lived body; and the Buddhist philosophical idea of dependent origination, specifically that cognition and the experienced world co-arise in mutual dependence. The basic idea of the enactive approach is that the living body is a self-producing and self-maintaining system that enacts or brings forth relevance, and that cognitive processes belong to the relational domain of the living body coupled to its environment. One implication of this idea is that cognition requires the exercising of capacities for skillful action and that even abstract cognitive processes are grounded on the body's sensorimotor systems, including the brain systems that, as we would say today, emulate sensorimotor processes in an "offline" way. This idea of cognition as based on modal sensorimotor systems is central to the approach called "grounded cognition," where "grounded" means based on body states, situated action, and modal perception-action systems.

From the enactive perspective, mindfulness practices should be viewed as forms of skillful cognition for enacting certain situated mind-body states and behaviours, not as a form of inner observation of a private mental realm. Notice that this contrast - between understanding meditation as a kind of enactive cognition versus as a kind of inner mental observation - is a conceptual and phenomenological one. Notice also that each conception has implications for cognitive science. On the one hand, thinking of mindfulness meditation as inner observation of a private mental realm feeds the internalist tendency in cognitive neuroscience to model mindfulness as a kind of mental activity instantiated in neural networks inside the head and visible through brain imaging tools such as EEG and fMRI. This approach often confuses the biological conditions for mindfulness with mindfulness itself, which, as classically described, consists in the integrated exercise of a whole host of cognitive and bodily skills in situated and ethically 
directed action. On the other hand, thinking of meditation as the enactment of situated mind-body states and behaviours requires us to distinguish clearly between the causally enabling conditions for mindfulness, which include neural systems but are not limited to them, and the cognitive processes that constitute mindfulness as a meaningful form of human experience, and that cannot be understood properly unless described phenomenologically. This is one way in which thinking through the enactive approach returns us to phenomenology and the primacy of meaning.

Here is how I plan to proceed for the rest of this lecture. My next step will be to use Western phenomenology to elaborate this idea of the primacy of meaning. I will then critically examine two ways that Buddhist philosophy has recently been positioned in relation to Western philosophy of mind and cognitive science. One is Owen Flanagan's "Buddhism naturalized" and the other is Dan Arnold's critique of what he calls "Buddhist reductionism." Finally, I will examine the relevance of certain Buddhist philosophical ideas about reflexive awareness for cognitive science. My hope is that these remarks can provoke further discussion at tomorrow's sessions.

\section{The Primacy of Meaning}

It is important to distinguish between scientific research on the mind, which is fundamentally important for our understanding of ourselves, and a certain philosophical position that we can call scientific naturalism. Scientific naturalism is the position that science provides the best account of reality or the world. Scientific naturalism has an ontological component and a methodological component. The ontological component is what philosophers call "physicalism," the thesis that everything that exists, including the mind, is physical. The methodological component is the thesis that the methods of empirical science give science a general and final authority about the world, and therefore empirical science should be privileged over all other forms of investigation. In arguing for the primacy of meaning I will be arguing against scientific naturalism, especially the methodological thesis that empirical science should be privileged over every other form of investigation. The implication of my argument for the Buddhism-cognitive science encounter will be that this encounter cannot be a genuine dialogue if it is premised on scientific naturalism.

As we go forward, it is crucial to remember that scientific naturalism is a philosophical thesis, not a thesis belonging to the practice of science itself. Although some cognitive scientists espouse scientific naturalism, it is not built into the very project of cognitive science. Moreover, when a scientist gives voice to scientific naturalism, he or she no longer speaks just as a scientist. As Husserl wrote in 1913: "When it is actually natural science that speaks, we listen gladly and as disciples. But it is not always natural science that speaks when natural scientists are speaking; and it is assuredly not when they are talking about 'philosophy of Nature' and 'epistemology as a natural science'."

The first point I want to make about scientific naturalism is that its ontological and methodological components stand in tension. The ontological component is the physicalist thesis that everything that exists is physical. For this thesis to be meaningful we need some way to define what "physical" means. But this demand gives rise to a dilemma (first stated by Carl Gustav Hempel and known as "Hempel's dilemma"). On the one hand, if we define "physical" as what physics today tells us is physical, then physicalism is probably false, because our present conception of the physical is limited, 
subject to revision, and insufficient for explaining mental phenomena. On the other hand, if we define "physical" as what some future, ideal physics would say is physical, then the claim that everything that exists is physical is empty, because we have no idea what it means. Suppose that we introduce a priori conceptual constraints on what "physical" can mean. Once we take this route, we are doing metaphysics, so we can no longer maintain that empirical science is to be privileged over all other forms of investigation. In other words, we have to give up the methodological thesis of scientific naturalism and use distinctly philosophical methods proper to the space of meaning.

What if we drop the ontological component and say that what matters for scientific naturalism is just the insistence on the methodological priority of science? This brings us to the core problem with scientific naturalism.

The basic complaint to be made about scientific naturalism is that it presupposes something as a necessary condition of its own possibility that it overlooks and cannot account for by itself. Western phenomenologists have given different names to what this is.

Husserl called it "transcendental consciousness," by which he meant consciousness not as an object of empirical investigation - for example, a biological or psychological property of certain organisms - but rather a necessary condition of possibility for any entity to appear as an object in whatever way that it does and with whatever meaning that it has, including everything that science is able to disclose. Anything that shows up for us or that we are able to disclose through whatever means presupposes consciousness in this transcendental sense. Husserl also described whatever shows up as belonging to what he called the "sphere of immanence." By this term he did not mean that what shows up or is disclosed to us is really contained within the mind. Rather, he meant that whatever has the meaning or sense of being "outside" or "beyond" consciousness - that is, whatever is "transcendent" in his technical sense - has this meaning or sense by dint of the synthesizing functions of consciousness, and hence falls within the sphere of what gets constituted as meaningful, that is, within the space of meaning. From this perspective, what scientific naturalism overlooks and does not have the methods to address is the transcendental role that consciousness plays in the constitution of meaning.

The problem with this account, as Husserl himself recognized, is that although there can be no space of meaning without consciousness, meaning does not present itself as originating in a private subjective sphere but as belonging to the shared world in which we find ourselves, or what Husserl came to call the life-world. Hence transcendental consciousness must be understood not as the consciousness of a single, individual subject, but as what Husserl called transcendental intersubjectivity, that is, consciousness as communally, socially, and historically situated, and as directed toward the common life-world. From this perspective, what scientific naturalism presupposes but overlooks is the primacy of the shared life-world, without which science would not be possible.

Husserl conceived of empirical science in relation to the life-world in the following way. Concrete experience of the life-world is the implicit departure point from which we create objective knowledge in roughly two steps. First, we set aside features of our concrete sensuous experience that vary individually and cannot be the object of a stable consensus. Second, using general propositions and mathematics, we create an abstract and formal representation of certain invariant and structural features of what we experience under rigorously controlled conditions, and this formal model becomes an 
object of consensus and the basis for an objective description. Scientific models, according to this account, are formalized representations of the world as disclosed to conscious experience and consist of structural invariants for some group of conscious subjects. Put another way, objective descriptions map structural and dynamical features of how the world is disclosed to us at various spatiotemporal scales and of how we are able to act on or intervene in processes at those scales. Scientific models and tools are distillations of our conscious experience as observers, modelers, and interveners. In this way, science never steps outside of the shared life-world and takes up some absolute standpoint on it. Science can enlarge the horizon of the life-world and open up new vistas, but it cannot get beyond the horizon of the life-world as its necessary condition of possibility.

Heidegger too used the word "world" to describe what scientific naturalism presupposes and overlooks. By "world" he meant neither the totality of things nor the being of that totality as nature, but the everyday world as the place where we find ourselves and as an existential structure of our being. We exist as being-in-the-world and not simply as a thing of nature in the universe. The expression "being-in-the-world" does not mean that we are in the world in the way that water is in a glass, but that we always find ourselves inhabiting a space of meaning that we ourselves create. Moreover, we are acquainted with the world in this sense in advance of any particular apprehension of something in the world, including any scientific apprehension. When we think of the universe or nature as containing our world, we are not thinking of the world in its proper philosophical sense as the space of meaning in which anything is intelligible. When we think of the world in this philosophical way, then we have to reverse the formulation and say that the universe or nature is within the world, for it is always within the world that the universe or nature is disclosed. In this way, the world as the space of meaning has priority in the order of philosophical inquiry and understanding over the universe as represented by empirical science.

I can now summarize the problem with scientific naturalism. Scientific naturalism basically remains oblivious to this priority of the world as the space of meaning and does not recognize the need for specifically philosophical methods, especially phenomenological ones, for investigating and understanding it. Empirical science investigates things in the world but does not investigate the space of meaning as such. For that kind of investigation, we need philosophy.

The relevance of these considerations for the Buddhism-cognitive science encounter is threefold. First, for this encounter to be a genuine dialogue, it has to begin from the recognition that the space of meaning is precisely what needs to be negotiated in the encounter. Second, the dialogue cannot be premised on the assumption of scientific naturalism, because this assumption forecloses the possibility of a full dialogue in which each tradition can challenge the other's assumptions, positions, and arguments. Third, Buddhist philosophy is the critical dialogue partner in this effort, not meditation as an object of scientific investigation.

\section{Buddhism Naturalized}

To illustrate these points, let me briefly contrast my approach to what Owen Flanagan calls "Buddhism naturalized." Flanagan thinks that because Buddhist epistemology has an empiricist bent, it has the internal resources sufficient to "naturalize" itself. By this he 
means making Buddhism — or what historians would call Buddhist modernismconsistent with scientific naturalism, especially physicalism. From my perspective, this approach, although advertised as a cosmopolitan dialogue, amounts to cultural assimilation and appropriation - assimilating certain Buddhist ideas to one particular Western viewpoint, instead of allowing the encounter to subject that Western viewpoint, too, to philosophical scrutiny.

Let me make clear that my point here is not to defend traditional Buddhist ideas (such as karma or rebirth) against Flanagan's rejection of them as inconsistent with our modern scientific worldview. It is rather to point out that in his call to naturalize Buddhism, Flanagan views Buddhism entirely through the lens of scientific naturalism, instead of allowing Buddhist philosophy to reflect back critically on scientific naturalism and to contribute to the dialogue more generally.

Consider the position Flanagan calls "subjective realism," according to which, "Conscious mental states are physical states that have an epistemically irreducible phenomenological or experiential character." This proposition raises a host of questions: What does "physical" mean, other than signaling the rejection of dualism? What is it for a state to be a conscious state? What is the relationship between the experiential character of a mental state and the intentional object or content of a mental state? How do we have knowledge of conscious mental states? These questions preoccupied Indo-Tibetan Buddhist philosophers for millennia, but Flanagan does not ask how they or contemporary philosophers informed by their work might respond to him. Consequently, his way of engaging with Buddhist thought about the mind falls short of an open and full dialogue.

Moreover, Flanagan's naturalism seems premised on a particular way of thinking about nature, one which the Madhyamaka school of Buddhist philosophy would call into question. From the Madhyamaka perspective, Flanagan's concept of the "natural" looks like what Madhyamaka would call a reification - something believed mistakenly to have its own intrinsic identify specifiable apart from how it is conceptually encountered. The Madhyamaka arguments (which I cannot rehearse here) that challenge this concept of intrinsic identity imply that whatever counts as "nature" cannot be understood apart from human cognitive practices of investigating nature, and therefore cannot be given absolute explanatory primacy over mind, contrary to the basic premise of Flanagan's naturalism. Once again, the intelligibility of nature resides within the world as the space of meaning - the space of the conventional or everyday world, in Madhyamaka termseven if we can also say that nature contains the world.

\section{Conceptualism}

A different approach is found in Dan Arnold's work. His book, Brains, Buddhas, and Believing: The Problem of Intentionality in Classical Buddhist and Cognitive-Scientific Philosophy of Mind, is oriented precisely toward issues about the space of meaning, and therefore stands as a model of the kind of dialogue we need. I agree with Arnold about the irreducible importance of a transcendental perspective (in the Kantian sense) on meaning. We differ, however, over how to understand the space of meaning. The principal point of my critique will be that the space of meaning is richer than the space of cognitive judgement; hence we should not equate the two. 
Arnold's principal concern is intentionality - the meaningful directedness of the mind toward its objects. His target is reductionistic accounts of intentionality, that is, accounts that would explain intentionality in terms of non-intentional, causal relations. Classical cognitive science provides one kind of reductionism. According to the computational theory of mind, mental states are computational states of the brain whose content derives from non-intentional information processing and causal interactions with the environment. In the Indian Buddhist tradition, Dharmakīti's philosophy, according to Dan's reading, provides a different kind of reductionism. For Dharmakīrti, mental phenomena consist of momentary, particular cognitions, in causal succession. Mental phenomena, so understood, are entirely impersonal, event-causal occurrences. For Dharmakīrti, perception is non-conceptual and unmistaken - it apprehends causally efficacious particulars - whereas thought or conception is mistaken - it apprehends unreal mental constructs (nominal universals). Furthermore, perception apprehends its object by way of a phenomenal aspect or form ( $\bar{a} k \bar{a} r a)$. When Dharmakīrti speaks from an externalist (Sautrāntika) perspective, he describes the phenomenal aspect as an imprint left on the mind by the causal influence of the external object and whose function is to represent the object. When he speaks from an internalist (Yogācāra) perspective, there is no appeal to external objects to explain perception but only an appeal to the aspect as a phenomenal object-appearance. Finally, for Dharmakīrti, every mental episode is selfintimating or reflexively aware of itself. Thus Dharmakīti's reductionism, on Dan's reading, consists in supposing that intentionality is ultimately reducible to the causation of non-conceptual, momentary, successive, and self-intimating perceptual events.

Arnold argues that classical cognitive science and Buddhist reductionism, despite their many differences, share the same basic flaw, which is that intentionality, specifically the conceptually structured, reason-giving practices of persons, cannot be explained in impersonal, event-causal, and non-conceptual terms. He relies on arguments from the Western lineage of Kant, Wilfrid Sellars, and John McDowell that aim to show that our conceptual capacities and their exercise in cognition-what Kant called "spontaneity" - cannot be explained in merely causal, non-intentional terms, but instead must be seen as sui generis. One of Arnold's central lines of argument is a Kantian style transcendental argument to the effect that the intentional level of reason-giving explanation is ineliminable in principle because any attempt to eliminate it in favour of impersonal causal explanations would have to appeal to reasons. So, too, the first-person perspective of reason-giving is ineliminable, because for me to understand anyone as responsive to reasons requires as a necessary condition of possibility that I understand the other person as doing what I do when I experience myself as acting for a reason. Arnold also uses arguments from the Buddhist Madhyamaka lineage (Nāgārjuna and Candrakīrti) in order to establish that the conventional level of persons engaged in reason-giving practices is not eliminable from an account of the world, and so cannot be explained in terms of ultimately real impersonal events, as Dharmakīrti's reductionism seems to require. Here the thought is that the categories of cause and effect have meaning not by being based on an impersonal objective reality, but by being conventional and pragmatic, reflecting the explanatory interests and practices of persons, and so they cannot be used to eliminate the conventional reality of persons in favour of an impersonal event-causal description. To summarize, Arnold aims to show that the intentional or meaningful order of persons - what I have called the space of meaning - cannot be eliminated from any 
account of how the world really is, and therefore that neither Buddhist nor cognitive science versions of reductionism provide acceptable accounts of the mind.

Although I agree with Arnold's insistence on the ineliminability of the space of meaning, I do not agree with what I would call his conceptualist or intellectualist account of the constitution of meaning in experience. By this I mean his view that something counts as an experience only insofar as its content is expressible by us as the content of a judgement. This view implies that we are not able to experience anything that outstrips our conceptual or judgement-forming capacities, or to put it another way, that nonconceptual content either does not exist or can play no constitutive role in what we experience.

Conceptualism, so understood, seems extreme. It fails to recognize modes of experience whose content is not equivalent to the content of a judgement. Such experiential content includes the feeling of being alive as an affective awareness of one's living body; the phenomenal structure of body-oriented space and the motor intentionality of directed action; the passive and auto-synthesizing flow of timeconsciousness; the perceptual presence of qualities, such as particular determinate shades of colour, that are not reidentifiable from moment to moment; the background affect of existential moods such as anxiety, boredom, despair, joy, or elation; and the possibility of immersed flow states and meditative states of absorption or heightened awareness that do not have a subject-object structure (most Indian philosophical systems recognize the possibility of such states).

Conceptualism also seems implausible from a cognitive science perspective, because it implies that there exists a sharp break between adult human experience and infant experience, as well as between human and other animal forms of experience. Conceptualism therefore makes it difficult to see how there could be the developmental and evolutionary emergence of conceptual capacities on the basis of pre-conceptual experience.

Debates about conceptuality and experience are lively in philosophy of mind and cognitive science, and they were lively in Indian philosophy (Buddhist and nonBuddhist). In my view, Arnold does not give these debates a proper cross-cultural hearing but instead assumes the Western conceptualist position as an unquestioned vantage point from which to criticize Dharmakīrti and his philosophical progenitor, Dignāga. In this way, Arnold treats the space of meaning and the space of judgement, as well as the everyday, conventional world in the Madhyamaka sense, as if they were equivalent. But if the space of meaning comprises non-conceptual modes of experience, then it cannot be equivalent to the conceptual space of judgement. In addition, I do not see how the Madhyamaka conception of conventional truth or conventional reality can be compatible with conceptualism, given the Madhyamaka commitment to the possibility of a direct, non-conceptual cognition of the emptiness of phenomena (their lack of intrinsic reality).

Arnold ties together two distinct issues. One issue is whether the space of meaning is the same as the space of judgement, and the other is whether intentionality is intelligible or explainable in impersonal causal terms. We can recognize that intentionality is not intelligible or explainable in impersonal terms while also recognizing that non-conceptual modes of experience contribute to the constitution of the space of meaning, so that it exceeds the space of judgement. Indeed, the recognition of both these 
points has been central to Western phenomenology from Husserl to Merleau-Ponty to Dan Zahavi today.

In my view, these insights from phenomenology make it an important interlocutor in the Buddhism-cognitive science dialogue. Phenomenology can help to bridge between cognitive science and Buddhist philosophical ideas about the mind. For the last part of my lecture, I want to illustrate this proposal for the case of the Yogācāra Buddhist concept of reflexive awareness.

\section{Reflexive Awareness}

The concept of reflexive awareness (svasamvedana) entered Buddhist philosophy in the writings of Dignāga (ca. 480-540), the founder of Buddhist logic and epistemology. His well-known "memory argument" for reflexive awareness occurs in the chapter on perception of his seminal text, Pramānasamuccaya, or "Compendium of Valid Cognition." In the verses immediately preceding the memory argument, Dignāga presents several arguments to establish that every cognition has a twofold appearance - that of its object and that of itself, or that of the object apprehended and that of the apprehending of the object. I want to examine the first of these arguments before we look at the memory argument, because it contrasts with the memory argument in a useful way.

The argument concerns the cognition of cognition, or what cognitive scientists call "metacognition." For example, I can recollect the visual cognition I had yesterday of seeing the blue sky. This is a case of one cognition (the present memory) taking another cognition (the past visual cognition) as its object. I can also attend to and think about my present visual perception, or think about my dream experience in a lucid dream. Cognitive scientists call this kind of meta-cognition "meta-awareness," because it is directed toward the present contents of awareness. (Let me note parenthetically that, on the Yogācāra view, meta-awareness involves a time lag, so strictly speaking it is retrospective, and one is said to cognize the immediately antecedent cognition.) Dignāga takes it as uncontroversial that our cognitive abilities include metacognition, and he argues that we cannot explain this fact unless we suppose that cognition is dual-aspected. In other words, if we assume that cognition has only one aspect, either that of the object or that of itself, then we will not be able to explain how it is possible for there to be the cognition of a cognition.

The argument goes as follows. On the one hand, suppose that cognition consists only of the object aspect. It follows that when I think about the visual cognition I had yesterday of seeing the blue sky, the object aspect of the present memory (namely, the past cognition) is the same as the object aspect of the past cognition (namely, the blue sky). But this implies the absurd consequence that the two cognitions are indistinguishable (they have the same object aspects and all there is to a cognition is its object aspect). On the other hand, suppose that cognition consists only of its own aspect (call this the subject aspect). It follows that they cannot be differentiated according to their content (they have no differentiating content and are exactly similar in regards to their subject aspects), so again we have the absurd consequence that they are indistinguishable. If we suppose, however, that cognition is dual-aspected, and that the object aspect of the present memory is the subject aspect of the past cognition, then the two cognitions are distinguishable. Thus, in metacognition, one cognition takes another 
cognition as its object, but under the apprehending aspect of that cognition. In this way, the model of cognition as being dual-aspected is able to account for metacognition.

Dignāga's thought is that when I metacognitively attend to one of my experiences I attend to an aspect of its content but that aspect cannot be the object aspect - the aspect of the apprehended; it must be the subject aspect - the aspect of the apprehending. Jonardon Ganeri offers the following useful analogy:

A painting of a painting is not the same as a duplicate of the original, and taking a photograph of a photograph is not the same as ordering a second set of prints. The second photograph takes the first as its object, and if the first photo was over-exposed, then the object of the second is an over-exposed photograph. This is perhaps the rationale behind Dinnāga's claim that, when one is introspectively thinking about one of one's own thoughts, the subjective aspect of the latter becomes the objectual aspect of the former. That is, the objectual aspect of a second-order thought $=$ the subjective aspect of its first-order thought. The double aspect theory of mental states is thus motivated as being the only way by which one can distinguish between thoughts and thoughts about thoughts, the intentional object of the latter being the subjective aspect of the former.

From a cognitive science perspective, Dignāga's argument has the form of an inference to the best explanation - the best explanation of metacognition is that cognition is dual-aspected. From a phenomenological perspective, the argument has the form of a transcendental argument - a necessary condition of possibility for metacognition is that cognition is dual-aspected.

We're now ready for Dignāga's memory argument. This argument aims to establish that every cognition - that is, every episode of awareness - is reflexively aware of itself, which means that it is aware of itself as dual-aspected, where this includes its having access to each aspect (here I follow Birgit Kellner's interpretation). Reflexive awareness, it is crucial to note, is not metacognition. On the contrary, in the course of his argument for reflexive awareness, Dignāga tries to rule out metacognition as able to account for the memory phenomenon that he thinks we need reflexive awareness to explain. Moreover, as we will see, Dignāga's view seems to be that reflexive awareness is a necessary condition for any access to mental phenomena and hence that it is a necessary condition for metacognition.

The memory argument has two parts. The first part tries to establish that in having an experience, there is an experiencing of the experience; the second part tries to establish that this experiencing of the experience is not due to a higher-order cognition of the experience, that is, it is not due to metacognition.

1. Here is my reconstruction of the first part of the memory argument:

2. When one remembers yesterday's blue (say, of the sky), one remembers not just the blue, but also the seeing of blue. In this way, the memory includes both the perception's object aspect (the apprehended, the object as seen) and its subject aspect (the apprehending, the seeing).

3. To remember something, one must have experienced it. 
4. Therefore, at the time of the visual perception, there must have been an experience of seeing, along with the object seen.

Let me note a few things about this argument from the perspective of the cognitive science of memory. First, the type of memory to which the argument appeals is episodic memory (memory of personal experiences), not semantic memory (factual knowledge). Second, the type of episodic memory is field memory (memory from the first-person perspective of the original experience), not observer memory (memory of the scene from an outside third-person perspective). Third, although memory always involves a creative re-imagination of the past from the standpoint of the present, it is based on re-enacting aspects of the brain patterns and body states that were originally generated in response to an event, and thus brings back to life not just what was experienced (the object aspect) but how it was experienced (the subject aspect), though both are also subject to constant elaboration. Dignāga's argument thus goes to the core of episodic memory as a cognitive process that brings back not just past events but how it was to experience those events. The point of the argument is that given that memory brings back not just the past event but how it was for one to experience the event, then one must have experienced one's experiencing of the event at the time.

One might object that the argument, if successful, can establish only that reflexive awareness belongs to episodes of awareness that are or can be remembered, but not to all episodes of awareness. One way to meet this objection is to add the following premise to the argument (which I take to be a suppressed premise in Dignāga's argument): For any episode of conscious awareness, it is remembered (or it can be), if only just immediately afterward and for a short time.

One way to motivate this premise, from a cross-cultural philosophical standpoint, would be to draw from Husserl's phenomenology of time-consciousness. According to his analysis, each present phase of consciousness has an built-in retention of the just-past phase. For example, in the experience of listening to a melody, the present phase of consciousness includes a retention of the just-heard notes. For Husserl, retention is not a separate act of recall but a necessary function built into every episode of awareness, and it is a necessary condition of possibility for the phenomenon of recall - it holds and maintains the content that recall is later able to access. Moreover, for Husserl, retention directly implies reflexive awareness, because any given present phase of consciousness retains the just-past phases of its apprehended object (the object aspect) only by way of retaining the just-past phases of its conscious apprehending of the object (the subject aspect): I am aware of the notes of the melody as slipping into the past only through my awareness of the notes as having just been heard by me. Thus, for Husserl, not only is consciousness reflexively aware of itself in retention, but it must be retentionally selfaware in order to be aware of objects across time. In this way, he argues, timeconsciousness entails reflexive awareness. (I note parenthetically that, in Indian philosophy, as Alex Watson and Dan Arnold have discussed, the Śaiva philosopher, Bhața Rāmankaṇtha, made a similar argument and used it to argue, against the Buddhists, that there is a self and that it is the same as the temporal unity and continuity of consciousness.)

The second part of Dignāga's argument is an infinite regress argument designed to show that metacognition cannot account for the remembered experience of experiencing. If we accept that at the time of seeing blue there must have been an experience of the 
seeing as well as of the blue, there seem to be two options: either the visual perception reflexively experienced itself (Dignāga's view) or it was cognized by another secondorder cognition. If we appeal to metacognition, however, then an infinite regress is said to ensue, because this second-order cognition too is remembered, and therefore experienced, requiring a third-order cognition, which is remembered, and therefore experienced, and so on.

Dignāga is assuming that the second-order cognition is itself an episode of conscious awareness. Nevertheless, in order to get the infinite regress going, we need the premise, mentioned earlier, that for any episode of conscious awareness, it is remembered (or it can be) if only just immediately afterward and for a short time. With this premise, the infinite regress does ensue (as Jonardon Ganeri has shown), with the absurd consequence that, as Dignāga says, cognition could never move on to a new object, because it would be stuck generating a non-halting iteration of higher- and higher-order metacognitions.

Suppose we say, however, that the second-order cognition is not conscious, and so cannot be remembered, and therefore no infinite regress need arise. Dignāga does not consider this idea, which we find in contemporary higher-order thought theories of consciousness, as well as in the non-Buddhist Indian Nyāya tradition. The problem with this idea, however, is that it is very difficult to see how a non-conscious cognition could make an otherwise non-experienced cognition into an experienced one. This is the standard complaint made against higher-order theories of consciousness today.

Although there are other technical problems with Dignāga's infinite regress argument, I will not discuss them here. What I want to call to your attention is that Dignāga's memory argument, as well as the vast subsequent Buddhist philosophical and contemplative literature on reflexive awareness, concerns an issue also at the heart of phenomenology and cognitive science, including the cognitive neuroscience of meditation, namely, how is it possible for us to have access to our own mental lives?

What I take to be the deep insight at the core of Dignāga's memory argument is that reflexive awareness, to quote Birgit Kellner, "is an immediate, non-conceptual mode of awareness that provides access to how mental content (including feelings, etc.) presents itself subjectively." The alternative is to suppose that we have access to how mental content presents itself subjectively only via metacognition. Of course, we do have metacognitive access to mental content, but Dignāga's insight — an insight consonant with Western phenomenology and with the cognitive science of memory, especially in its embodied or grounded cognition versions - is that metacognitive access presupposes a pre-conceptual acquaintance with the embodied and subjective aspect of our mental lives - an embodied experiencing of experience that metacognition does not constitute on its own but that it can make explicit. Here it is helpful to remember that the word "vedana" in svasamvedana means "feeling," so that what Dignāga seems to be talking about is the reflexive and pre-conceptual feeling of being aware in being aware, or to use a phenomenological idiom, the feeling of being alive in being sentient. (I owe this observation to Alex von Rospatt.) Seen this way, it is no surprise, I think, that Śāntarakșita later says that reflexive awareness is what distinguishes sentience from insentience: the nature of sentience is reflexive awareness and that which is not reflexively aware is insentient. To the objection that an act cannot be directed toward itself but must be directed toward an object, Sāntarakṣita replies that reflexive awareness 
does not have an agent-action-object structure. In other words, reflexive awareness is not a form of object-directed intentionality, though it is a necessary constitutive feature of such intentionality.

The last point I want to make about the concept of reflexive awareness is that it seems to be a necessary conceptual underpinning to a unique concept of meta-awareness that Buddhist scholars (John Dunne) and cognitive scientists (Antoine Lutz, Cliff Saron, and Amishi Jha) have been working together to elaborate in the context of the cognitive neuroscience of mindfulness. In this context, meta-awareness is one of several dimensions along which mindfulness practices can vary. It means the capacity to note implicit features of experience, such as background affect, but without shifting one's attentional focus away from wherever it may be located, and specifically without turning one's attention inward in an introspective way. Roughly speaking, the idea is that certain mindfulness practices enhance or enliven reflexive awareness, but without turning one's attention inward and thereby objectifying one's prereflective experience. From a phenomenological perspective, such practices could be described as heightening one's sensitivity to what Merleau-Ponty calls the phenomenal field of the lived body. They provide an example of how certain mindfulness practices should not be thought of as the inner observation of an independent mental stream, but rather as the enactment of a certain kind of embodied sensitivity to the phenomenal field of one's living body.

I want to conclude this lecture by calling attention to a crucial issue that I have so far overlooked. Despite the points of contact between Buddhist philosophy, cognitive science, and phenomenology that I have tried to sketch, there remains a fundamental difference in perspective between Buddhist philosophy, on the one hand, and cognitive science and Western phenomenology, on the other. The difference derives from the soteriological framework of Buddhism - the Buddhist concern with enlightenment and liberation. For example, from the Yogācāra perspective, the subject-object structure of ordinary consciousness is inherently distortive in relation to the ultimate, non-dual nature of the mind. Even everyday modes of experience that do not have a subject-object structure, such as absorbed skillful action or immersed flow states, would be seen as ignorant or deluded compared to realizing the non-dual nature of the mind. Furthermore, although the dual-aspected structure of consciousness is innate, it is not essential and can be seen through or removed - and the soteriological project, at least as Yogācāra philosophy construes it, is precisely to do this. This soteriological view is allied to the view that reflexivity, although required for intentionality, is ontologically prior to intentionality, and is nothing other than the "luminosity" of the mind. This view contrasts with Western phenomenology, in which reflexivity and world-directed intentionality are inseparable. It also raises the question of whether a purely reflexive and non-intentional state could be said to have any kind of content, and whether, from a cognitive science perspective, there is any way to model such a state. How should the Buddhism-cognitive science encounter approach such normative and metaphysical differences in their views about the mind? My hope is that this question may be productive for our discussions tomorrow.

\section{Conclusion}

I began this lecture by saying that the Buddhism-cognitive science encounter should take its direction from philosophy by giving primacy to the constitution of meaning in human 
experience, and that Buddhist philosophy must be central to this effort. I hope to have shown the merits of this proposal, and I hope to have illustrated one way in which we might begin to take this step. 